\title{
Occipito-suboccipital neonatal giant encephalocele
}

\author{
Anuj Kumar Tripathi ${ }^{1}$, Saurabh Pathak, ${ }^{2, *}$ \\ ${ }^{1}$ Assistant Professor, ${ }^{2}$ Associate Professor, Dept. of Surgery, ${ }^{1,2}$ Career Institute of Medical Sciences and Hospital, Lucknow, Uttar Pradesh, \\ India
}

*Corresponding Author: Saurabh Pathak

Email: drsaurabhpathak@yahoo.com

\begin{abstract}
Encephalocele is a type of Neural tube defect. Encephaloceles are rare but giant encephaloceles are very rare. Giant encephalocele means that encephalocele size is greater than maximum head circumference. It may contain cerebrospinal fluid (csf), meninges, brain and venous sinuses. These cases are challenging to Neurosurgeon, Neuro anaesthetiest, neuro radiologist and Nursing care staff. In our retrospective study we analyzed occipito-suboccipital neonatal giant encephalocele and review the Literature.
\end{abstract}

Keywords: Giant encephalocele, Head-circumference, Neural tube defect, Neonate Occipito-suboccipital region.

\section{Introduction}

Encephalocele is a Neural tube defect. Giant encephalocele means encephalocele diameter is greater than maximum diameter of Neonatal head (Fig. 1). Incidence of neonatal giant encephalocele is $3.6 \% .^{1}$ It may contain cerebrospinal fluid, meninges, brain and venous sinuses (Fig. 2). These cases are challenging to Neurosurgeon, Neuroanaesthesia, neuroradiologist and Nursing care staff. Anesthesia in these cases is challenging due to large posterior Encephalocele, intra operative blood loss and hypothermia. $^{2-4}$ In our retrospective study we analyzed occipito-suboccipital neonatal giant encephalocele and review the Literature.

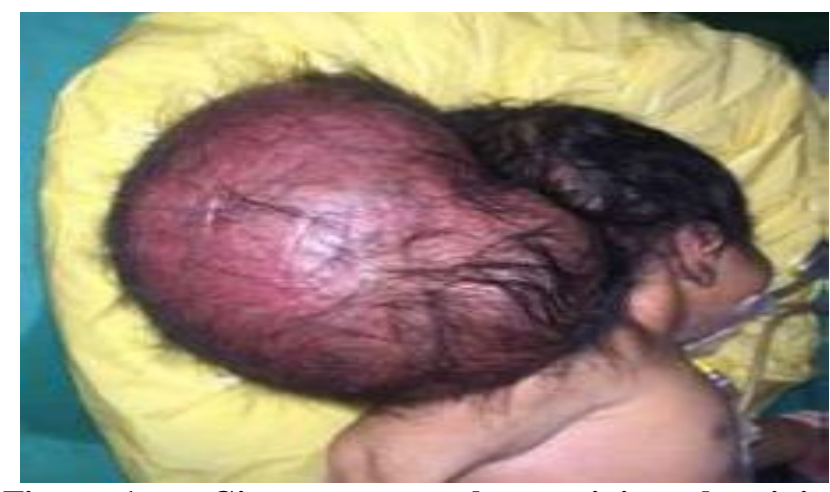

Fig. 1: Giant neonatal occipito-suboccipital encephalocele.

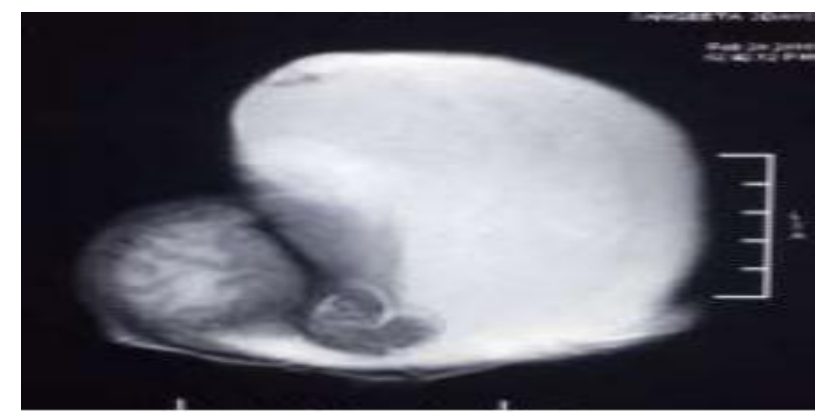

Fig. 2: Giant neonatal occipito-suboccipital encephalocele with herniated brain

\section{Materials and Methods}

In this study, we analyzed 4 cases of giant occipitalsuboccipital Neonatal Encephalocele. Computed tomography (CT) and magnetic resonance imaging (MRI) were done in all 4 cases. Two cases had Hydrocephalus for which Ventriculopenitoneal shunt was done before definitive surgery (Fig. 3).

In all cases, meninges, gliosed brain and csf were present in the sac. Excision of sac was done and removed the gliosed brain (Fig. 4). There were no venous sinus herniation. Dura was closed tightly. Wound was healthy in post operative period (Fig. 5). Post operative period was uneventful and discharged on 15 to 18 days from Neonatal ward.

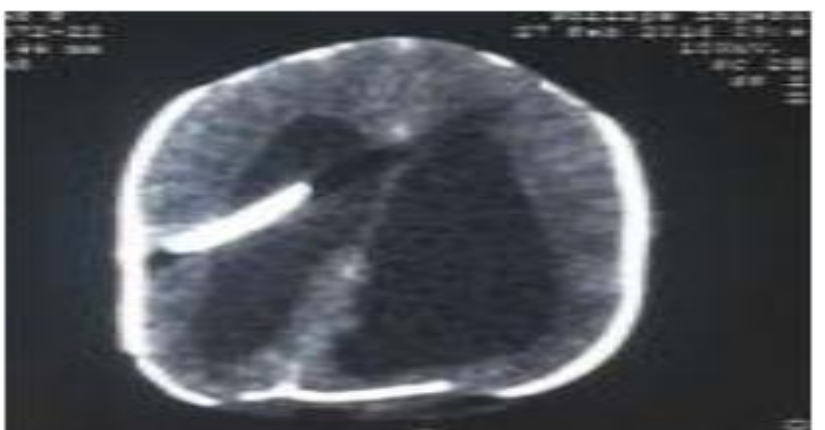

Fig. 3: Ventriculo peritoneal shunt for hydrocephalus in giant encephalocele

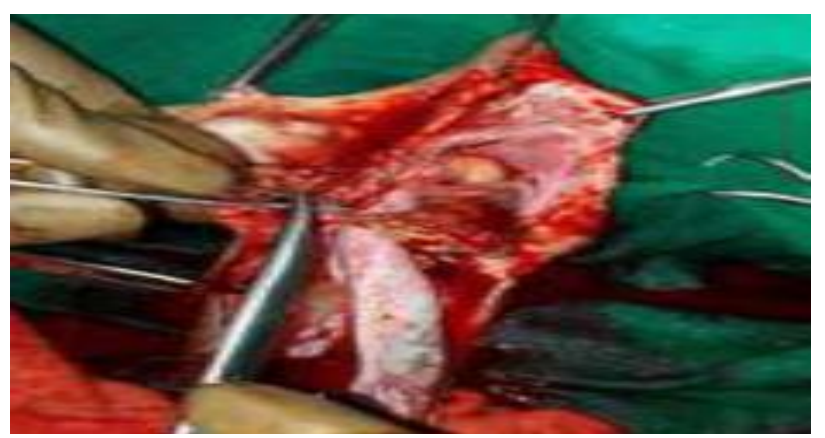

Fig. 4: Excision of sac and removal of the gliosed brain 


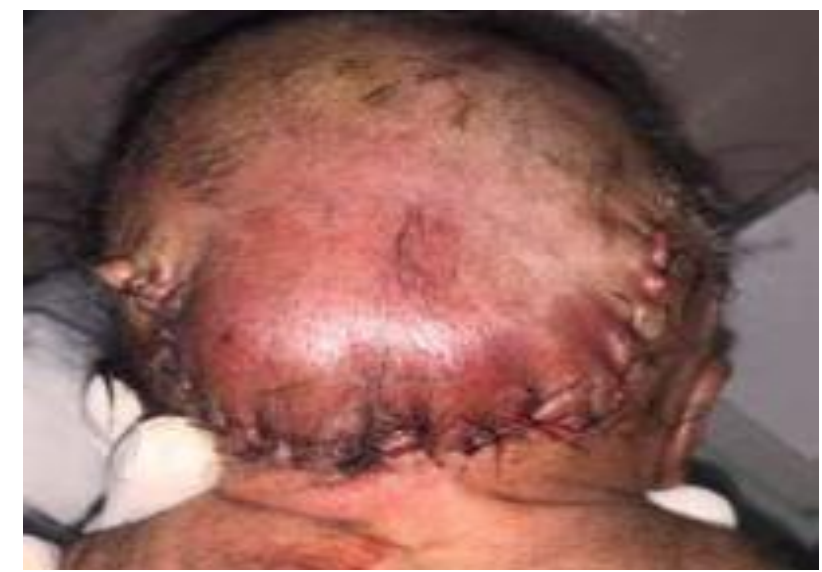

Fig. 5: Post operative image after excision of the encephalocele

\section{Discussion}

Giant Encephalocele means diameter of encephalocele is greater than maximum diameter of brain. ${ }^{2,3,5,6}$ It is a type of Neural tube defect with incidence of 3.6\%. ${ }^{1}$ On review of literature, we found a single case series of giant encephalocele. ${ }^{1}$ Anterior encephaloceles are more common in male and posterior encephalocele are commonly seen in female. In our sevies two cases were male and two cases were female.

MRI is the gold standard investigation for these cases. It detects the soft tissue, brain abnormalities, contents of encephalocele and status of venous sinuses. CT Head detects the bone defect only. Radiation is very high in CT Head and not good for soft tissue structures. In our all cases CT Head and MRI Brain with spinal was done. In these cases other brain abnormalities like Hydrocephalus ${ }^{1}$ Dandy waiker cyst ${ }^{1,5,7}$ microgyria, craniostenosis microcephaly, Chiari II malformation, syringomyelia. and micrognathia may present. ${ }^{1}$ In our two cases Hydrocephalus was present.

Due to large encephalocele, intubation in supine position is difficult. With the help of towel, we raised the body and made frog like position so that encephalocele can properly accommodate the head ring and we can properly intubate the patient. Other methods include Lateral position ${ }^{8}$ placing the head beyond the table ${ }^{9}$ and aspiration of Encephalocele before surgery. ${ }^{1}$

During surgery, these is excision of sac, herniated gliosed brain with preservation of viable brain, vital brain structures and venous sinus. Tight dural closure is must for these cases. In our series, we excised the herniated sac, gliosed brain with preserving of viable and vital brain material. Other surgical methods are expansile cranioplasty ${ }^{10}$ and partial excision of herniated viable brain material. ${ }^{1}$ Intra operative blood loss, hypothermia, bradycardia and cardiac arrest are well known complication. ${ }^{2,3,4}$ Post operatively hydrocephalus, infection and CSF Leak is also seen in few cases. No such complications are seen in our group.

\section{Conclusion}

Till date management of Giant Neonatal occipitalsuboccipital encephalocele is challenging to Neurosurgeon, Anesthetiest, Radiologist and Nursing care staff. Expertization is necessary for these cases.

\section{Conflict of Interest: None.}

\section{References}

1. Mahapatra AK: Giant encephalocele: A study of 14 patients. Pediatr Neurosurg 2011;47:406-411.

2. Satyarthee GD, Mahapatra AK: Craniofacial surgery for giant frontonasal encephalocele in neonate. J Clin Neurosci 2002;9:593-595.

3. Mahapatra AK, Gupta PK, Dev EJ: Posterior fontanelle giant encephalocele. Pediatr Neurosurg 2002;36:40-43.

4. Bharti N, Dash HH, Mahapatra AK: Recurrentbrady-cardia and delayed recovery in aneonate following repair of nasofrontal encephalocelewith hosopresencephaly and single cerebral ventricle. J Neurosurg Anesthesiol 2003;15:140-143.

5. Todo T, Usui M, Araki F: Dandy-Walker syndrome forming a giant occipital meningocele - case report. Neurol Med Chir (Tokyo) 1993;33:845-850.

6. Mahapatra AK: Giant encephalocele. A series of 21 cases (abstract). Childs Nerv Syst 2007;27:1082.

7. Hokum singh, Daljit singh, DP Sharma, Monica S Tandon, Pragati Ganjoo: Perioperative challenges in patients with giant occipitalencephalocele with microcephaly and micrognathia jnrp. 2012;3:68-70.

8. Bissonnette B. Pediatric neuroanaesthesia: Beyond the theory. In: Badgewell IIM, editor. Clinical Pediatric Anaesthesia. 1st ed.Philadelphia: Lipincott Raven 1997;339-345.

9. Walia B, Bhargava P, Shandu K. Giant occipital encephalocele. MJAFI 2005;61:293-294.

10. Bozinov O, Tirakotai W, Sure V, Bertalanffy H: Surgical closure and reconstruction of a large occipital encephalocele without parenchymal excision. Childs Nerv Cyst 2005;21:144147.

How to cite this article: Tripathi AK, Pathak S, Topic: Occipito-suboccipital neonatal giant encephalocele. Indian $J$ Anat Surg Head Neck Brain 2018;5(1):29-30. 